\title{
EXERCÍCIOS ESPIRITUAIS ONLINE - É POSSÍVEL OFERECER ESPIRITUALIDADE PELA EAD?
}

\author{
VALINHOS/SP AGOSTO/2018 \\ Lisa Paula Reis Branquinho－UNICAMP - lisapaularb@hotmail.com \\ Tipo: Investigação Científica (IC) \\ Natureza: Descrição de Projeto em Andamento \\ Categoria: Pesquisa e Avaliação \\ Setor Educacional: EDUCAÇÃO CONTINUADA EM GERAL
}

\begin{abstract}
RESUMO
Os cursos online oferecidos por meio de plataformas de Educação a Distância geralmente têm seu foco no oferecimento de conteúdos e disseminação do conhecimento. Em alguns casos, podem até mesmo dar ênfase a atividades práticas, mas seria possível utilizar esta plataforma tão dedicada ao desenvolvimento do raciocínio para promover uma experiência transcendente? Foi essa a proposta que a equipe da EAD Século fez aos padres jesuítas: disponibilizarem os Exercícios Espirituais de Inácio de Loyola pela plataforma Moodle. Ao trazer esta proposta para a pesquisa de mestrado na área de Linguística Aplicada, tenho como objetivo analisar a mediação digital (THOMPSON 2011) que nela acontece, para verificar como ela se distingue da sua versão presencial e se houve perdas e ganhos no processo de remidiação (BOLTER 2000). Além disso, utilizarei a Linguística de Corpus (SARDINHA 2000) para analisar as partilhas realizadas pelos fóruns e a Gramática Sistêmico-Funcional (THOMPSON 2014) para verificar como os participantes representam sua experiência no discurso.
\end{abstract}

Palavras-chave: religião; mídias; linguística do corpus; EAD

\section{AGRADECIMENTOS}

A TODA EQUIPE DA EAD SÉCULO 21; AO PE. EDUARDO DOUGHERTY,SJ E PADRES JESUÍTAS DA VILA KOSTKA; AOS ACOMPANHANTES QUE SE DEDICAM AOS EE ONLINE; AO PROF. MARCELO BUZATO, MEU ORIENTADOR NESTA PESQUISA. 


\section{1 - Introdução}

Este trabalho em andamento, fruto de uma pesquisa na área de Linguística Aplicada, busca apresentar o potencial da EAD para além da educação. A proposta pesquisada traz a adaptação de uma prática tradicional e experiencial, os Exercícios Espirituais de Inácio de Loyola (EE), que perdura por séculos, com o intuito de que ela deixe de ser um privilégio de poucos, que têm acesso presencial aos seus locais de oferecimento e se expanda via tecnologia da EAD, remidiando-se para chegar aos lugares mais longínquos.

Conforme afirma Barthes (1990), os Exercícios Espirituais são um manual de ascese universalmente enaltecido e "não é preciso ser jesuíta, nem católico, nem cristão, nem crente, nem humanista para interessar-se por eles".

Apresento aqui um histórico dos EE e da EAD Século 21, plataforma onde a proposta inovadora foi apresentada; explico como foi organizada a proposta, como foi a adesão e quais os principais desafios. Em seguida, apresento o referencial teórico com o objetivo de analisar a mediac?a?o digital (THOMPSON 2011) que acontece na proposta online, e se houve perdas e ganhos no processo de remidiac?a?o (BOLTER 2000). Ale?m disso, utilizarei a Lingui?stica de Corpus (SARDINHA 2000) para analisar as partilhas realizadas pelos fo?runs e a Grama?tica Siste?mico-Funcional (THOMPSON 2014) para verificar como os participantes representam sua experie?ncia no discurso.

\section{2 - O que são os Exercícios Espirituais de Inácio de Loyola}

Inácio de Loyola viveu de 1491 a 1556 e tornou-se, de cavaleiro defensor do império, a militante do Reino de Deus. Ele fundou a Companhia de Jesus, religiosos conhecidos mundialmente como jesuítas, e propagou uma maneira de encontrar a Deus por meio dos EE. Inácio comparava os EE a exercícios corporais como passear, caminhar e correr. De diferentes maneiras, cada pessoa deve buscar examinar a consciência, meditar, contemplar para encontrar a vontade de Deus na sua vida (LOYOLA, 2011).

Desse modo, os EE foram organizados em forma de roteiros que foram propagados por todo o mundo e muito influenciaram a espiritualidade da Igreja Católica. Até hoje, os jesuítas continuam pregando os Exercícios Espirituais. Leigos e religiosos de diversas partes do mundo se reúnem em grupos, em casas de retiros, em locais de silêncio e oração para fazerem essa experiência.

A forma clássica em que os EE são propostos se realiza em uma casa de retiros, em 
que o exercitante dispõe de 30 dias seguidos para ficar em silêncio e oração. Cada semana desse retiro tem um tema específico proposto por Inácio de Loyola e cada dia da semana tem os seus roteiros e meditações bíblicas para serem seguidas em cada período do dia. O silêncio só é interrompido uma vez ao dia quando entra em cena a figura do diretor espiritual ou acompanhante, que geralmente é um padre jesuíta, uma religiosa ou um leigo que já vivenciaram os EE e que fizeram uma formação específica para exercerem essa função. O exercitante relata ao acompanhante como foram os seus períodos de oração, quais foram as suas dificuldades e qual foi o seu progresso no caminho espiritual.

E para facilitar para aqueles que não têm a possibilidade de parar 30 dias em uma casa de retiros, foi criada a modalidade "exercícios na vida cotidiana" (EVC). Na forma EVC, o exercitante busca reservar um momento de meditação por dia que conciliará com as outras atividades do seu cotidiano. Uma vez por semana, o grupo de exercitantes se reúne com o seu acompanhante para relatar como foi o seu progresso na prática dos exercícios e receber auxílio e orientações para perseverar nessa prática.

\section{3 - Como surgiu a EAD Século 21}

Foi também um sacerdote jesuíta, Padre Eduardo Dougherty, que idealizou a EAD Século 21 como uma proposta de formação integral da pessoa - humana, cristã, profissional, comportamental - para que o conhecimento seja difundido a um número irrestrito de pessoas.

A EAD Século 21 surgiu, primeiramente, apenas como um site de vídeos sob-demanda. Aos poucos, os vídeos passaram a videoaulas e começaram a ser acompanhados de apostilas, questionários de avaliação, fóruns de debates, tutoria e certificados de conclusão, disponibilizados pela plataforma Moodle.

Desde 2009, quando a plataforma foi criada, já foram produzidos mais de 300 cursos livres com duração aproximada de 30 dias. Os temas são diversos, desde espiritualidade, oração e estudos bíblicos, a culinária, comportamento, administração e negócios. Em sua maioria, os cursos são oferecidos gratuitamente e organizados por professores voluntários, há também alguns que foram produzidos em parcerias com instituições ou empresas.

Cerca de 150.000 estudantes já passaram pela plataforma desde o final do ano de 2010, quando foi inaugurada, até meados de 2018. O público tem uma idade variada, atingindo desde a adolescência à idade avançada, tendo predominância de acessos de pessoas 
entre 30 e 55 anos. Mulheres representam 61\% e homens compõem 39\% do total.

Em boa parte das parcerias feitas com empresas e instituições, a busca pela EAD Século 21 se deve ao fato de terem uma demanda muito grande de pedidos para que o curso seja aplicado por todo o país, porém as limitações de tempo e geográficas são graves impeditivos para atender a todos os pedidos presencialmente. É nesse contexto que a EAD se torna uma facilitadora para a acessibilidade a tais conteúdos.

\section{4 - Exercícios Espirituais na EAD Século 21}

Os cursos online oferecidos por meio de plataformas de Educação a Distância geralmente têm seu foco no oferecimento de conteúdos e disseminação do conhecimento. Em alguns casos, podem até mesmo dar ênfase a atividades práticas, mas seria possível utilizar esta plataforma tão dedicada ao desenvolvimento do raciocínio para promover uma experiência transcendente?

Foi essa a proposta que a equipe da EAD Século fez aos padres jesuítas: disponibilizar os Exercícios Espirituais de Inácio de Loyola pela plataforma Moodle. E para que isso fosse possível, foram necessárias diversas adaptações e remidiações.

\section{1 - Principais atores}

4.1.1 - O Coordenador do projeto - um padre jesuíta, Pe. José Ramón Cigoña,sj, que assumiu a coordenação do projeto e se reuniu com a equipe para formatar a proposta. Ele se encarregou de selecionar a equipe de conteudistas e de acompanhantes.

4.1.2 - Os conteudistas, formados por padres e leigos que gravaram os vídeos com as propostas dos EE e também pelos padres que organizaram a apostila com os textos de apoio aos vídeos.

4.1.3 - Os acompanhantes, que são os tutores responsáveis por conduzir as atividades e orientar pessoalmente cada um dos exercitantes de seu grupo.

4.1.4 - Os exercitantes, que se inscreveram gratuitamente pelo site. Eles não têm, necessariamente, formação prévia sobre os exercícios. No entanto, há também um número grande de exercitantes que já participaram dos EE em casas de retiros.

4.1.5 - A equipe da EAD Século 21 que formatou o projeto; gravou os vídeos; treinou os conteudistas e os acompanhantes que, em sua maioria, não conheciam a plataforma 
Moodle; ofereceu suporte e orientações técnicas para os exercitantes.

\section{2 - A organização da proposta}

Foi seguindo o modelo dos EVA (Exercícios na Vida Cotidiana) que os EE online foram propostos. No total, são oferecidos 125 temas para os exercícios online, propostos em vídeos de 10 minutos. Esses temas são divididos em 4 etapas, chamadas de módulos. Além de assistir aos vídeos, cada exercitante precisa reservar ao menos 30 minutos por dia para sua oração pessoal. Cada vídeo traz para o exercitante uma proposta de exercício espiritual, uma orientação para a contemplação, um roteiro para o seu tempo de oração silenciosa.

Após terminar esse período de oração, ele fará suas anotações pessoais descrevendo como foi a sua experiência e quais são as suas dificuldades em progredir no caminho proposto.

A interação dos acompanhantes com os exercitantes acontece dentro de um Fórum de Partilhas, pelo qual o exercitante é convidado a compartilhar com o acompanhante e colegas de grupo as anotações feitas. Os acompanhantes também têm a liberdade de entrar em contato com os exercitantes via mensagem individual, e-mail ou videoconferência, quando se faz necessária uma orientação individual.

\section{3 - $A$ adesão}

Já nos primeiros meses de oferecimento da proposta, houve um grande retorno positivo. A busca por participar dessa experimentação inovadora foi grande, divulgada pela televisão e pela internet, inclusive em um site oficial do Vaticano.

Os 4 módulos da proposta têm uma duração total de 6 meses, sendo oferecido um vídeo por dia, de segunda a sexta-feira. A primeira turma iniciou os exercícios em julho de 2016 e finalizou em dezembro do mesmo ano. Depois dela, já foram iniciadas mais 5 turmas contando com um total de 5.363 inscritos.

Tabela 1 - número de participantes inscritos em cada turma
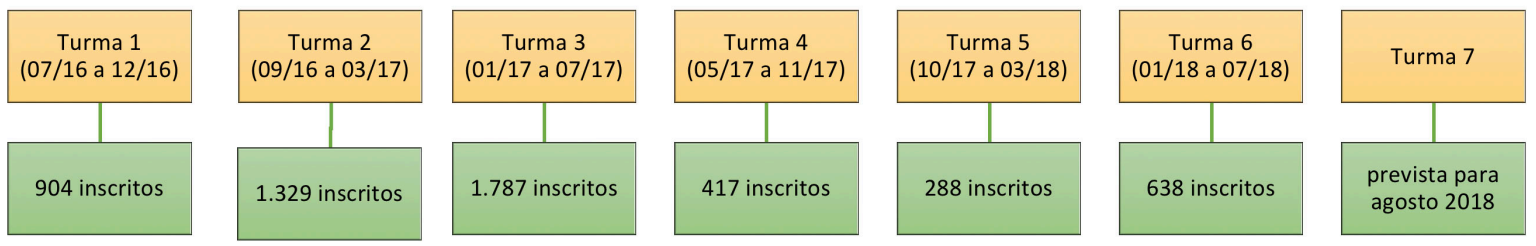
Fonte: EAD Século 21

\section{4 - Principais Desafios}

Os Exercícios Espirituais têm foco em uma experiência que será realizada fora do ambiente virtual. O objetivo principal dos EE é que o exercitante tenha um encontro com Deus e dialogue com ele sobre sua vida e ações do dia-a-dia, que tenha atitudes de mudança para se tornar uma pessoa cada vez melhor.

Apesar de se utilizar de diversas mídias para acompanhar o exercitante, o objetivo da prática dos EE via EAD é que ele tenha uma experiência com Deus no momento em que deixa de lado todas as mídias propostas para estar a sós com Ele, em oração.

O desafio também é lidar com os contextos interacionais múltiplos e simultâneos (LEANDER, 2008): o ambiente EAD, o ambiente físico e o ambiente interno da reflexão e contato com o divino. Quando a proposta dos exercícios é vivenciada em uma casa de retiros, o local e todo o contexto ao redor - silêncio, natureza, afastamento das preocupações cotidianas - auxiliam na experiência espiritual proposta. No meio digital, há uma multiplicidade enorme de atividades comunicativas concorrentes que podem dispersá-lo do objetivo final.

\section{5 - Objetivos e Referencial Teórico}

Ao trazer esta proposta para a pesquisa de mestrado na área de Linguística Aplicada, tenho como objetivo analisar a mediação digital (THOMPSON 2011) que nela acontece, para verificar como ela se distingue da sua versão presencial e que perdas e ganhos houve no processo de remidiação (BOLTER 2000).

\section{1 - Remidiação}

Bolter (2000) diz que a remediação é um processo pelo qual as novas mídias aproveitam elementos das mídias antigas para superá-las, ao mesmo tempo em que as mídias antigas se renovam incorporando os elementos novos trazidos pelas mídias mais recentes. $O$ autor diz ainda que os processos de remidiação são formas de preencher nosso desejo aparentemente insaciável da imidiação, isto é, de um contato direto com as experiências no mundo que as mídias representam.

Bolter aponta para a nossa como uma cultura que deseja igualmente multiplicar suas mídias (hipermidiação) e apagar os traços da mediação que elas exercem (imidiação), 
ou seja, quer apagar as mídias que separam o intérprete da experiência, no próprio ato de multiplicá-las. Já nos Exercícios Espirituais, que buscam trazer uma experiência transcendente, mesmo com a utilização de mídias como a Bíblia, o caderno de anotações, a caneta, seria possível experimentar a imidiação?

E na proposta online, a hipermidiação seria um impeditivo para isso? O número de mídias utilizadas, os PDFs com manuais, os vídeos com tutoriais, as videoaulas, os emails, os fóruns do moodle seriam distrações e empecilhos para que a proposta de fato atendesse às expectativas de quem a procura e atingisse os objetivos esperados?

\section{2 - Novas mídias no processo}

$\mathrm{Na}$ adaptação dos EE para o contexto online, algumas poucas pessoas, acostumadas com a forma tradicional de praticá-los, chegaram a rejeitar o projeto, dizendo que essa proposta não poderia ser chamada de Exercícios Espirituais, pois havia se transformado em outra coisa. Gitelman (2006) fala sobre a agência e a possibilidade de ação humana sobre as mídias. No momento em que novas mídias foram incorporadas à prática tradicional, não somente a prática pode ser vivenciada de modo diferente como também a mídia pode ser utilizada para fins diferentes a que foi proposta.

No caso dos EE online, a partilha que acontece presencialmente entre o acompanhante e o exercitante, utilizando como mídias a Bíblia, o caderno de anotações, a caneta e as anotações passam por um processo de remidiação que inclui a apresentação de vídeos com meditações, o uso de fóruns de partilhas, a mediação do computador e da internet para o acesso e do teclado e mouse como marcadores. Com isso, a prática é de fato vivenciada de outra maneira. Porém, o Moodle, que é uma plataforma de EAD, pode ser utilizada para um fim diferente do qual ela foi proposta inicialmente, ou seja, a vivência também pode transformar as tecnologias mediadoras.

\section{3 - Mediação Digital}

Thompson (2011) observa que "durante a maior parte da história humana, a grande maioria das interações sociais foram face a face", ou seja, em um contexto de copresença, em que os participantes têm a mesma referência de tempo e espaço. $\mathrm{Na}$ modernidade, os meios de comunicação afetaram os padrões tradicionais de interação social porque criaram novos tipos de interação que se estendem no espaço e no tempo, oferecendo um leque de características que as diferenciam das interações face a face. Ele divide tais eventos comunicativos em outros dois tipos principais: 
1 - Interação Mediada - aquela em que se usa um meio técnico que possibilite a transmissão de informação e conteúdo para indivíduos situados remotamente no espaço e/ou no tempo (por exemplo, carta, conversa telefônica, mensagens via internet);

2 - Quase-interação mediada - aquela que também se dissemina pelo tempo e espaço, mas, ao contrário das anteriores, é dirigida para um número indefinido de receptores potenciais, havendo uma comunicação de massa (ex: livros, jornais, rádio, televisão).

Os EE online têm um caráter híbrido, em que os vídeos e textos preparados antecipadamente para um número indefinido de receptores potenciais permitem apenas uma quase-interação mediada, enquanto os acompanhantes e exercitantes exercem, via fóruns, uma interação mediada.

Algumas deixas simbólicas, como gestos e expressões faciais presentes na interação face a face estão ausentes nesses novos tipos de interação, além da dilatação do tempo e do espaço que situa os participantes em contextos diversos e adiciona complexidade à comunicação.

Considerando esse caráter híbrido, a pesquisa prevê entrevistas com participantes que já realizaram os EE utilizando também interações face a face, de modo a construir um panorama dos 3 tipos de interação teorizados por Thompson.

\section{4 - Linguística do Corpus (LC) e Gramática Sistêmico Funcional (GSF)}

Todas as postagens feitas nos fóruns de partilhas do moodle de cada uma das turmas dos EE online foram coletadas criteriosamente para gerar um corpus linguístico (SARDINHA 2000).

As escolhas linguístico-discursivas que fazemos ao representar eventos e mudanças nos estados de coisas ao nosso redor são indícios do tipo e da qualidade de nossas experiências. A LC permite que se faça um levantamento estatístico das escolhas feitas em um Corpus. Já para estabelecer o vínculo entre essas escolhas e a experiência vivenciada, é preciso utilizar uma teoria sobre a relação entre a linguagem e o mundo. Neste caso, a teoria utilizada será a GSF. Entre outros motivos, porque essa teoria prevê que todo ato de linguagem traz em sua constituição um componente de sentido vinculado à experiência do falante no mundo, a assim chamada metafunção experiencial.

Conforme Thompson (2014) é necessário analisar a linguagem vinculada ao seu 
contexto. E a GSF oferece uma série de recursos para interpretar o texto agregando fatores como comunicação, cultura, interação. A metafunção ideacional / experiencial é a possibilidade que a linguagem oferece de falar sobre o mundo, representá-lo, transmitir e expressar ideias, pois a linguagem tem a capacidade de criar significados experienciais.

Para este trabalho, farei um recorte no corpus com o intuito de verificar como a metafunção ideacional/experiencial é utilizada nos fóruns de partilhas, buscando padrões interacionais que apontem como os exercitantes descrevem sua experiência dos Exercícios e como o acompanhante orienta a experiência que deve ser buscada.

\section{6 - Procedimentos Metodológicos}

A pesquisa acontece no campo da Linguística Aplicada tendo iniciado no ano de 2017 com previsão de término em 2019. Para a montagem do corpus, serão considerados os mais de 5 mil participantes que se inscreveram para as 6 turmas dos EE online durante os anos de 2016 a 2018. Para as entrevistas serão escolhidos cerca de 2 a 4 acompanhantes; um grupo de exercitantes que está participando dos Exercícios Espirituais pela primeira vez e um grupo de exercitantes que já têm experiência dos EE presenciais e que escolheu também experimentar a opção online.

A coleta de dados será feita da seguinte forma: as mensagens de todos os fóruns do moodle serão baixadas em planilhas do Excel e será feita uma filtragem inicial. Para as entrevistas, os grupos selecionados receberão um convite via e-mail para responderem a um questionário. A partir das respostas recebidas, serão escolhidos um a três participantes principais de cada grupo para entrevistas via Skype, que serão transcritas e analisadas da mesma forma.

Para a análise dos dados, será utilizado o software Sketch Engine no qual o corpus será organizado e analisado e será feito um levantamento das escolhas linguísticas que preenchem a metafunção experiencial, ou seja, de que tipo são os processos, os participantes e as circunstâncias mais frequentes e o que isso indica sobre a qualidade da experiência. Os dados dessa análise serão cotejados com os resultados das entrevistas para que se aprofunde a análise do ponto de vista qualitativo.

\section{7 - Considerações Finais}

Houve algumas resistências de quem recomendou não chamar esta proposta de EE por ser diferente da proposta original de Inácio, e de quem considerou que esta modalidade 
não poderia proporcionar o mesmo que a experiência presencial.

Nesse sentido, a pesquisa também pode contribuir para o campo da teologia fornecendo subsídios para a seguinte reflexão: em tempos passados, existia grande resistência para que as tecnologias digitais adentrassem o espaço da escola. Atualmente, elas já são importantes aliados às mais diversas possibilidades de metodologias ativas. $O$ percurso pode ser o mesmo para a espiritualidade ou não?

Também para o campo da EAD, a pesquisa pretende contribuir no sentido experiencial, levantando a possibilidade de compartilhar experiências que vão além da disseminação do conhecimento e da transmissão de conteúdos.

\section{8 - Referências Bibliográficas}

BARTHES, Roland. Sade, Fourier, Loyola. São Paulo, SP: Brasiliense, 1990. 174 p.

BOLTER, Jay David. Remediation and the Desire for Immediacy. Convergence, v. 6, n. 1 , p. $62-71,2000$

GITELMAN, L. Always Already New: Media, History and the Data of Culture. Cambridge: The MIT Press, 2006. (Introduction: Media as Historical Subjects, pp. 1-22)

LEANDER, Kevin M. Toward a Connective Ethnography of Online/Offline Literacy Networks, in Coiro J. et al (Eds) Handbook of Research on New Literacies, pp. 33-65. New York: Lawrence Erlbaum, 2008

LOYOLA, Inácio de. Escritos de Santo Inácio. Exercícios Espirituais. Edições Loyola, São Paulo, 2011, 5ª edição.

SARDINHA, Tony Berber. 2000. "Lingui?stica de Corpus: histo?rico e problema?tica". DELTA: Documentac?a?o de Estudos em Lingu?i?stica Teo?rica e Aplicada 16 (2): 323-367. doi:10.1590/S0102-44502000000200005.

THOMPSON, John B. The rise of mediated interaction. In: The media and modernity: a social theory of the media. Reprinted. Cambridge: Polity Press, 2011, p. 81-109.

THOMPSON,Geoff. IntroducingFunctional Grammar. ThirdEdition. BritishRoutledge, 2014. 